\title{
Influência da adição de filer de areia de britagem nas propriedades de argamassas de revestimento
}

\author{
Influence of crushed aggregates filler on the properties \\ of rendering mortar
}

\section{Claudio de Souza Kazmierczak \\ Mateus Rosa \\ Daiana Cristina Metz Arnold}

Claudio de Souza Kazmierczak Universidade do Vale do Rio dos Sinos São Leopoldo - RS - Brasil

Mateus Rosa Universidade do Vale do Rio dos Sinos São Leopoldo - RS - Brasil

Daiana Cristina Metz Arnold Universidade Feevale Novo Hamburgo - RS - Brasil

Recebido em 30/03/15 Aceito em 08/11/15

\section{Resumo}

$\mathbf{E}$ ste trabalho discute o efeito da variação do teor de adição de filer de areia de britagem nas propriedades de argamassas de revestimento produzidas com areias de britagem. Em um traço de argamassa 1:1:6, em volume, confeccionado com cimento CP II Z-32, cal classe CH-I e areia de britagem de rocha basáltica proveniente de britador tipo VSI, foram adicionados cinco diferentes teores de finos de britagem, determinadas suas principais propriedades, a retração em barras de argamassa, e o nível de fissuração de revestimentos aplicados sobre um substrato de cerâmica vermelha. Para os materiais utilizados, a adição de $10 \%$ de finos de britagem resulta em uma argamassa trabalhável, com melhoria em suas propriedades mecânicas e retração dentro de limites aceitáveis.

Palavras-chaves: Argamassa de revestimento. Areia de britagem. Filer de britagem. Fissuração de revestimentos.

\section{Abstract}

This article evaluates the use of crushed fine aggregates on rendering mortar produced with crushed sand. Mortar admixtures at 1: 1: 6 proportion (cement, lime, crushed fine aggregate, in volume) with CP II Z-32 Brazilian cement, CH-I lime, fine crushed basalt aggregate and five different percentages of filler made of crushed basalt were produced. The main properties and the shrinkage of the rendering mortar were evaluated. The use of $10 \%$ of filler results in a workable mortar with improved mechanical properties and shrinkage within acceptable limits.

Keywords: Rendering mortar. Basalt crushed fine aggregates. Filler from crushed basalt. Shrinkage. 


\section{Introdução}

A areia de britagem é um material proveniente do processo de cominuição mecânica de rocha, submetido ou não a algum processo de classificação para retirada do material pulverulento, com granulometria entre $4,8 \mathrm{~mm}$ e 0,150mm (ABNT, 2011). Segundo Gonçalves et al. (2007) o processo de cominuição e as características da rocha utilizada irão definir a distribuição granulométrica, a forma, aspectos superficiais e a integridade dos grãos manufaturados por britagem, e em consequência sua influência nas propriedades das argamassas. As características que mais distinguem as areias de britagem das areias de rio são a forma dos grãos, geralmente angulosa e com baixo grau de arredondamento; o elevado teor de material pulverulento (também chamado de filer de britagem); e a diferença de distribuição granulométrica, pois em função do tipo de processamento utilizado para a obtenção de agregados de britagem podem ocorrer falhas na produção de grãos em determinadas frações granulométricas.

A areia de britagem vem sendo cada vez mais utilizada em substituição aos agregados naturais, que se tornam escassos e mais caros. Entretanto, autores como Harini, Shaalini e Dhinakaran (2012) demonstram que as areias provenientes de britagem geram argamassas com menor trabalhabilidade que as confeccionadas com areia de rio devido à sua forma irregular e textura superficial.

Durante a cominuição do agregado miúdo de britagem, é comum a geração de elevados teores de filer de britagem, na ordem de 10 a $20 \%$. Como este teor é considerado elevado, no Brasil muitas destas areias somente são comercializadas após serem submetidas a lavagem para a sua remoção. Entretanto, segundo Ahn (2000), a adição de filer pode melhorar a trabalhabilidade e as propriedades mecânicas de uma argamassa com areia de britagem. Westerholm et al. (2008) afirmam que ao se adicionar uma grande quantidade de filer em uma argamassa com areia de britagem o limite elástico da argamassa é aumentado, além de ocorrer uma ampliação em sua deformação plástica. Os mesmos autores afirmam que as propriedades plásticas que o agregado confere à argamassa são fortemente influenciadas pelo volume de pasta da argamassa, sendo que o aumento do teor de pasta pode reduzir ou até mesmo eliminar os efeitos negativos de deficiências na distribuição granulométrica e da forma de grão inadequada. Desta forma, o uso de filer de britagem pode trazer melhorias à argamassa no estado fresco.

$\mathrm{Na}$ confecção de revestimentos de argamassa, entretanto, o uso de filer de britagem pode resultar em perda de aderência ao substrato e fissuração excessiva. Segundo Silva, Buest e Campiteli (2005) argamassas com elevado teor de microfinos (que correspondem à fração mais fina dos fílers) podem fissurar por retração, enquanto que as argamassas sem microfinos perdem a trabalhabilidade.

Em argamassas com areia de rio, Sampaio e Bastos (2009) constataram que o uso de microfinos aumenta a demanda de água da argamassa, em função do aumento da superfície específica. Por outro lado, como os microfinos possuem dimensões menores que o agregado miúdo, num primeiro momento eles preenchem os espaços vazios da areia, aumentando a compacidade da argamassa e tornando necessária a correção de sua trabalhabilidade. Como ao longo da retração resultante da evaporação da água não combinada existem restrições provenientes da aderência entre a argamassa e o substrato, é comum o aparecimento de fissuras. Miranda e Selmo (2006) afirmam que o controle do teor total de microfinos em uma argamassa é um parâmetro importante no controle da fissuração de revestimentos. Em argamassas com agregados provenientes de britagem, entretanto, o aumento da trabalhabilidade decorrente da adição de filer (e consequentemente de microfinos) pode superar a demanda de água decorrente do aumento de superfície específica.

Até determinada quantidade, o uso de microfinos aumenta a compacidade das argamassas. Este aumento da compacidade resulta em aumento da retenção de água da argamassa, o que pode prejudicar a sua aderência ao substrato (SARAIVA; BAUER; GONÇALVES, 2010).

Neste trabalho é avaliado o efeito da adição de filer de britagem nas propriedades e na fissuração de revestimentos com argamassas produzidas com areia de britagem. Em um traço de argamassa confeccionado com areia de britagem de rocha basáltica proveniente de britador tipo VSI, foram adicionadas cinco diferentes porcentagens de filer de areia de britagem, determinadas suas principais propriedades, a retração em barras de argamassa, e o nível de fissuração em revestimentos aplicados sobre um substrato de cerâmica vermelha. 


\section{Materiais e métodos}

O trabalho teve como objetivo determinar a influência da adição de diversos teores de finos de areia de britagem (filer basáltico) em argamassas de revestimento onde o agregado utilizado foi a areia de britagem (agregado miúdo proveniente da britagem de basalto). Foram confeccionadas argamassas mistas com cimento e cal hidratada, no traço $1: 1: 6$ (cimento Portland CP II Z - 32: cal hidratada $\mathrm{CH}$ I em pasta: areia de britagem basáltica seca, todos em volume), confeccionadas com areia natural proveniente de leito de rio (traço de referência) e com areia de britagem de rocha basáltica, obtida a partir de cominuição em britador do tipo VSI, na qual foram adicionados cinco teores de filer de origem basáltica $(1,5 ; 6$; $10 ; 20 ; 30 \%$ em volume). Estas argamassas foram utilizadas para a confecção de revestimentos aplicados sobre um substrato de blocos de vedação de cerâmica vermelha provenientes de uma olaria tradicional no Estado do RS.

As características físicas dos aglomerantes utilizados constam na Tabela 1, segundo dados fornecidos pelo fabricante.

A massa específica da areia de rio utilizada foi de $2,6 \mathrm{~g} / \mathrm{cm}^{3}$ e a da areia de britagem $2,7 \mathrm{~g} / \mathrm{cm}^{3}$. Os materiais apresentaram as seguintes massas unitárias: cimento $2,6 \mathrm{~g} / \mathrm{cm}^{3}$, cal $0,74 \mathrm{~g} / \mathrm{cm}^{3}$, areia de rio $1,55 \mathrm{~g} / \mathrm{cm}^{3}$, e a areia de britagem $1,71 \mathrm{~g} / \mathrm{cm}^{3}$. Os coeficientes de arredondamento e de esfericidade das areias, calculados segundo a NBR 7389-1:2009, constam na Tabela 2.
A distribuição granulométrica dos agregados miúdos e do filer utilizados pode ser visualizada na Figura 1. A areia de britagem basáltica foi lavada, foram removidas as frações maior que $2,4 \mathrm{~mm}$ e inferior a $0,075 \mathrm{~mm}$ e seus grãos foram redistribuídos de modo a apresentar a mesma distribuição granulométrica de uma areia natural de rio, considerada como referência. A Figura 1 também apresenta a distribuição granulométrica do filer utilizado, em sua granulometria original (com grãos até a peneira com abertura $0,150 \mathrm{~mm}$ ), obtida pelo método de difração de raios Laser, segundo o método especificado na Norma ISO 13320 (INTERNATIONAL..., 2009). O método empregado foi via úmida, com solvente água, num fluxo de $80 \%$, empregando ultrassom como meio dispersante, em $40 \mathrm{w}$, por 30 segundos. Apresentase também a curva obtida considerando apenas os grãos menores que $0,075 \mathrm{~mm}$. Também pode ser visualizada a distribuição granulométrica do cimento utilizado, como referência dimensional.

O filer de britagem foi adicionado ao agregado miúdo de britagem nos teores especificados previamente (variando de 1,5 a $30 \%$ ). Como $14,81 \%$ do filer tem dimensão superior a $0,075 \mathrm{~mm}$ (sendo $12,67 \% \leq \# 0,150 \mathrm{~mm}$ ), considerou-se que para fins de análise do comportamento das argamassas esta parcela deve ser somada ao agregado miúdo, o que resulta em uma pequena alteração na distribuição granulométrica dos agregados miúdos, que na adição de $30 \%$ de filer aumenta $3,7 \%$ a sua quantidade de finos. Os resultados desta adição na distribuição granulométrica do agregado miúdo podem ser visualizados na Tabela 3 .

Tabela 1 - Características físicas dos aglomerantes utilizados

\begin{tabular}{|c|c|c|c|c|c|}
\hline & Ensaio & Norma utilizada & média & unidade & limite \\
\hline \multirow{8}{*}{$\begin{array}{l}\stackrel{ }{\mathscr{D}} \\
\stackrel{\Xi}{0}\end{array}$} & Área Específica (Blaine) & NBR NM 76:1998 & 4748 & $\mathrm{~cm}^{2} / \mathrm{g}$ & $\geq 2600$ \\
\hline & Massa Específica & NBR NM 23:2001 & 2,99 & $\mathrm{~g} / \mathrm{cm}^{3}$ & não aplic. \\
\hline & Finura - Resíduos na Peneira de 0,075 mm & NBR 11579:2012 & 0,34 & $\%$ & $\leq 12,0$ \\
\hline & Finura - Resíduos na Peneira de 0,044 mm & NBR 12826:1993 & 3,12 & $\%$ & não aplic. \\
\hline & Água da Pasta de Consistência Normal & NBR NM 43:2002 & 29 & $\%$ & não aplic. \\
\hline & Início de Pega & NBR NM 65:2003 & 243 & $\min$ & $\geq 60 \mathrm{~min}$ \\
\hline & Fim de Pega & NBR NM 65:2003 & 308 & $\min$ & $\leq 480 \mathrm{~min}$ \\
\hline & Expansibilidade de Le Chatelier & NBR 1158:1991 & 0,35 & $\mathrm{~mm}$ & $\leq 5,0$ \\
\hline \multirow{2}{*}{$\bar{ల}$} & Massa Específica & NBR NM 23:2001 & 2,4 & $\mathrm{~g} / \mathrm{cm}^{3}$ & não aplic. \\
\hline & Finura - Resíduos na Peneira de $0,075 \mathrm{~mm}$ & NBR 1579:2012 & 8,3 & $\%$ & $\leq 12,0$ \\
\hline
\end{tabular}

Tabela 2 - Coeficientes de arredondamento e de esfericidade dos agregados miúdos

\begin{tabular}{ccccc}
\hline \multirow{2}{*}{$\begin{array}{c}\text { Peneira } \\
\text { (micrometros) }\end{array}$} & \multicolumn{2}{c}{ Arredondamento } & \multicolumn{2}{c}{ Esfericidade } \\
\cline { 2 - 5 } & Areia natural & Areia de britagem & Areia natural & Areia de britagem \\
\hline 1200 & 0,671 & 0,652 & 0,680 & 0,667 \\
600 & 0,729 & 0,660 & 0,743 & 0,739 \\
300 & 0,754 & 0,731 & 0,796 & 0,784 \\
150 & 0,780 & 0,739 & 0,823 & 0,816 \\
75 & 0,701 & 0,805 & 0,776 & 0,797 \\
\hline
\end{tabular}


Figura 1 - Distribuição granulométrica dos materiais utilizados

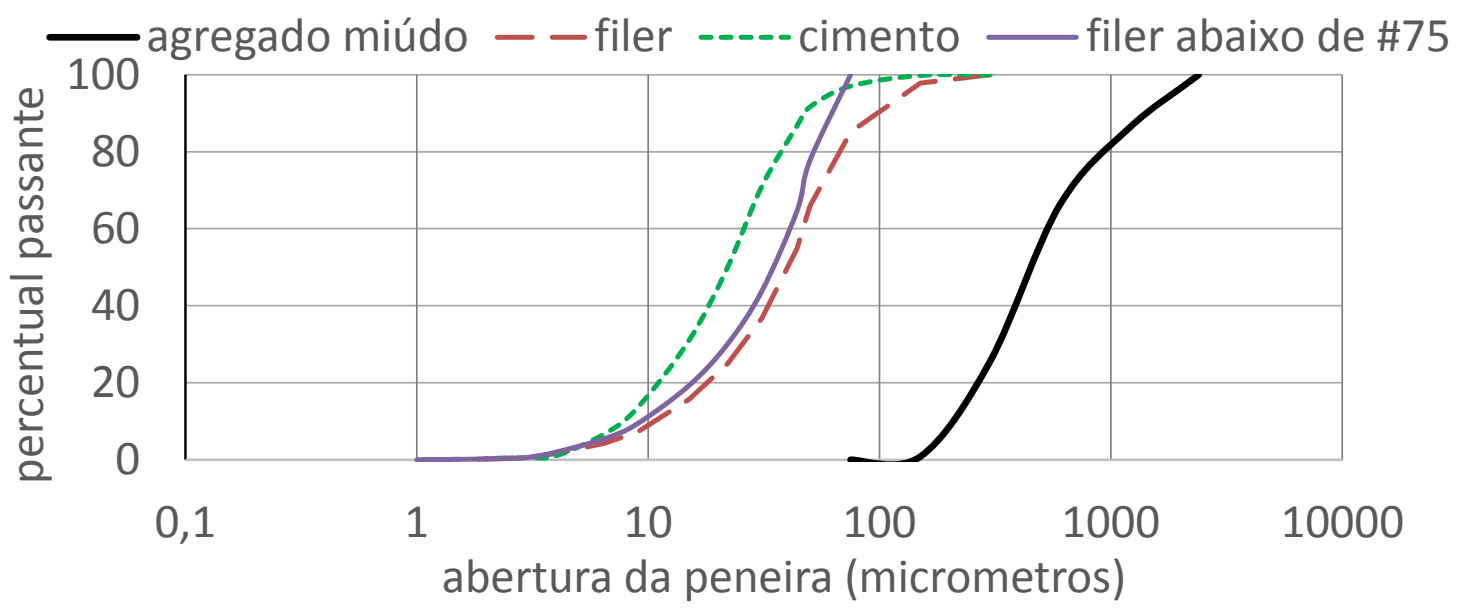

Tabela 3 - Alterações na distribuição granulométrica do agregado miúdo em função da adição de filer de basalto

\begin{tabular}{ccccc}
\hline $\begin{array}{c}\text { Peneira } \\
\text { (micrometros) }\end{array}$ & $\begin{array}{c}\text { Agregado miúdo } \\
\text { original }\end{array}$ & $\begin{array}{c}\text { Adição de } \\
\mathbf{1 , 5 \%} \text { de filer }\end{array}$ & $\begin{array}{c}\text { Adição de } \\
\text { 6\% de filer }\end{array}$ & $\begin{array}{c}\text { Adição de } \\
\mathbf{1 0 \%} \text { de filer }\end{array}$ \\
\hline 2400 & 100 & 100 & 100 & 100 \\
1200 & 86,16 & 86,2 & 86,29 & 86,37 \\
600 & 66,06 & 66,24 & 66,46 & 66,65 \\
300 & 25,43 & 25,69 & 26,19 & 26,65 \\
150 & 0,8 & 1,09 & 1,65 & 2,17 \\
75 & 0 & 0 & 0 & 0 \\
\hline
\end{tabular}

Observa-se que mesmo com uma adição na ordem de $30 \%$ de filer de basalto a alteração na distribuição granulométrica do agregado miúdo não é substancial, sendo percebida apenas nas frações mais finas.

A adição de filer ao agregado miúdo basáltico teve como objetivo melhorar as propriedades da argamassa com agregado miúdo de britagem, visto que a simples substituição da areia de rio pela areia de britagem em um mesmo traço normalmente resulta em uma argamassa inadequada para uso em revestimentos. A bibliografia afirma que os microfinos são responsáveis pelo acréscimo de resistência em concretos e argamassas (SILVA; BUEST; CAMPITELI, 2005), e que este fato provavelmente está relacionado à sua pequena dimensão (que gera aumento de compacidade ao agregado miúdo ao qual é adicionada), sua forma e rugosidade superficial. Neste trabalho foi utilizado filer de britagem (definido como partículas provenientes da britagem, composta por microfinos (partículas com dimensão $\leq 0,075 \mathrm{~mm}$ ) e um pequeno teor de agregado miúdo, que não foi separado por peneiramento). Na Figura 2 podem ser visualizados grãos de filer de areia de britagem utilizados nesta pesquisa, sendo possível identificar a elevada rugosidade superficial e sua forma irregular.

Os teores de filer adicionados às areias foram especificados em 1,5\% para a areia de rio utilizada como referência e em 1,$5 ; 6 ; 10 ; 20$ e $30 \%$ para a areia de britagem (a identificação dos traços pode ser vista na Tabela 4). A NBR 7211 (ABNT, 2005) estabelece que, para concretos, o máximo teor de filer constituído de materiais que tiveram origem em britadores pode ser de até $12 \%$, sendo que teores elevados são responsáveis por aumentar a retração e podem gerar fissuração. Outras normas, como a ASTM C 33, são mais rigorosas, estabelecendo como limite máximo a adição de $7 \%$ de filer passante na peneira de malha $0,075 \mathrm{~mm}$. Entretanto, não há referências normativas sobre este limite em argamassas de revestimento, e também não se pode extrapolar estes limites para a adição de filer em areias de britagem, que possuem características muito diversas das areias naturais de rio, para as quais os limites de adição foram estabelecidos.

Os módulos de finura das areias utilizadas ficaram entre 3,19 e 4,39, sendo todas classificadas como areias grossas, com base nos estudos de Bauer e Sousa (2005). Os coeficientes de uniformidade,

10 Kazmierczak, C. de S.; Rosa, M.; Arnold, D. C. M. 
considerando-se a abertura de peneiras correspondentes a $60 \%$ e a $10 \%$ de material passante, resultam que a areia natural é classificada como agregado de granulometria muito uniforme (coeficiente de uniformidade $=4$ ), com compacidade menor que a areia de britagem (coeficiente de uniformidade $=8$ ).
Na Figura 3 é possível visualizar a composição das argamassas no estado fresco.

A confecção, cura e os ensaios das argamassas e revestimentos foram realizados em ambiente de laboratório, sob temperatura de $23 \pm 2{ }^{\circ} \mathrm{C}$ e umidade relativa do ar de $60 \pm 5 \%$, conforme especificado na NBR 13276 (ABNT, 2005a).

Figura 2 - Visualização do filer de areia de britagem utilizado como adição, a partir de microscopia eletrônica de varredura

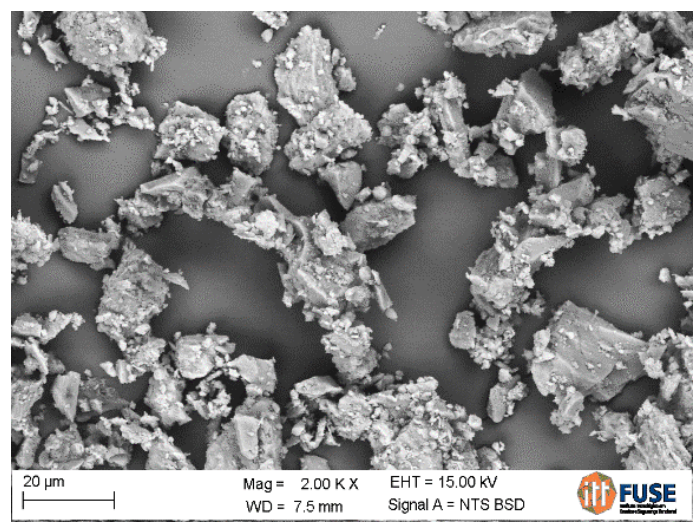

Tabela 4 - Identificação dos traços estudados e do teor de filer de areia de britagem adicionado

\begin{tabular}{ccc}
\hline Tipo de areia & Identificação & Teor de filer (\%) \\
\hline Areia Natural & AN1,5 & 1,5 \\
Areia de Britagem & AB1,5 & 1,5 \\
Areia de Britagem & AB6 & 6 \\
Areia de Britagem & AB10 & 10 \\
Areia de Britagem & AB20 & 20 \\
Areia de Britagem & AB30 & 30 \\
\hline
\end{tabular}

Figura 3 - Distribuição quantitativa de constituintes nas argamassas, em volume específico

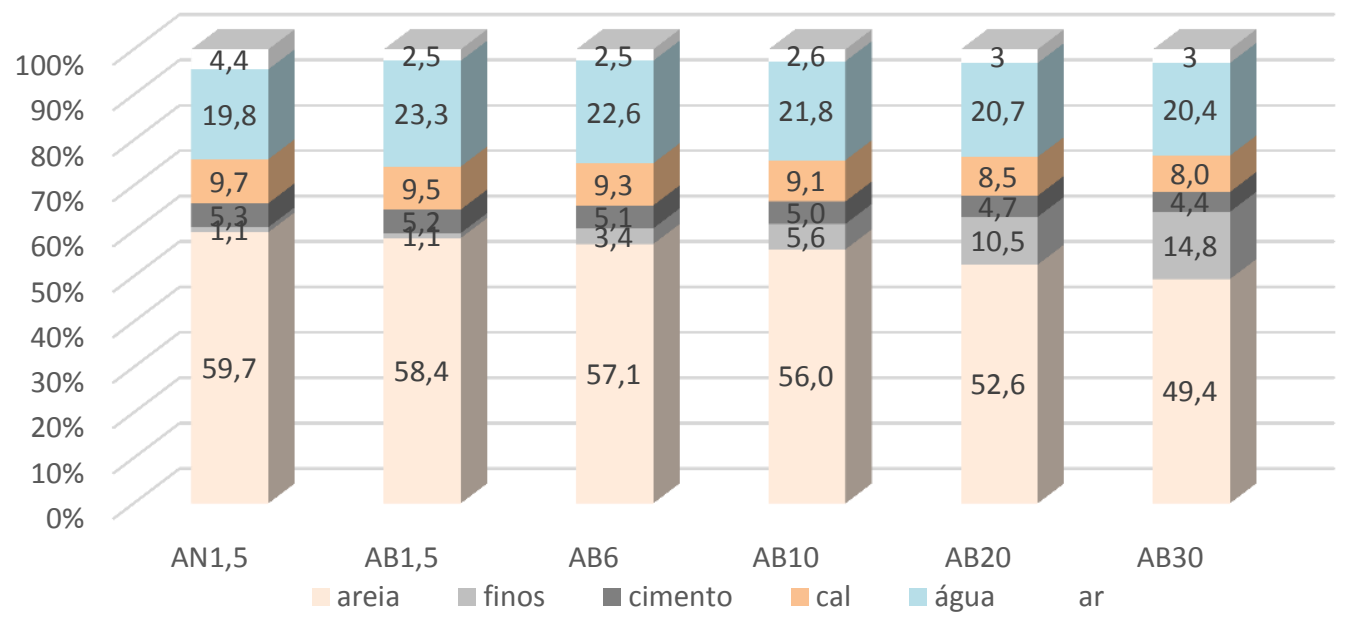


O índice de consistência por espalhamento das argamassas (ABNT, 2005a) foi estabelecido em $260 \pm 5 \mathrm{~mm}$, a partir do ensaio de espalhamento em mesa de consistência. A quantidade de água utilizada em cada traço de argamassa foi determinada de modo a atingir este índice de consistência. Embora o parâmetro adotado para a fixação do teor de água tenha sido a trabalhabilidade determinada por índice de consistência por espalhamento, também foi determinada a trabalhabilidade por Squeeze-flow (ABNT, 2010), que permite a avaliação do comportamento reológico das argamassas, identificando diferenças importantes para seu manuseio e aplicação, o que geralmente não é possível pelo ensaio de espalhamento. O ensaio com mesa de consistência é reconhecidamente insuficiente para a análise reológica de argamassas, pois, ao contrário do ensaio com Squeeze-flow, não é capaz de dissociar a contribuição da tensão de escoamento e da viscosidade na resistência ao fluxo da argamassa (CARDOSO et al., 2010). Os ensaios de Squeezeflow foram realizados com velocidade de $0,1 \mathrm{~mm} / \mathrm{s}$, após $15 \mathrm{~min}$ da mistura, em prensa universal de ensaios Emic modelo DL-2000 com célula de carga de $1000 \mathrm{~N}$. No estado fresco, ainda foram determinados o teor de água, a densidade de massa (segundo a NBR 13278 (ABNT, 2005b)), o teor de ar incorporado (NBR NM 47 (ABNT, 2002)) e a retenção de água das argamassas, segundo a NBR 13277 (ABNT, 2005c).

Para a determinação das propriedades das argamassas no estado endurecido, foram moldados corpos de prova prismáticos de 40×40×160mm para a determinação da resistência à compressão e a flexão - NBR 13279 (ABNT, 2005d), densidade de massa - NBR 13280 (ABNT, 2005e), módulo de elasticidade dinâmico - NBR 8802 (ABNT, 1985) com o uso de aparelho do tipo Pundit, considerando-se um coeficiente de Poisson 0,2, índice de vazios e absorção de água total - NBR 9778 (ABNT, 2009) e coeficiente de capilaridade NBR 15259 (ABNT, 2005f). A distribuição de poros das argamassas foi obtida pela técnica de porosimetria por intrusão de mercúrio, utilizandose um equipamento QuantaChrome PoreMaster, com pressão de intrusão de mercúrio de 0 a 227,37 $\mathrm{MPa}$, adotando-se um ângulo de contato de $130^{\circ}$, em amostras extraídas dos corpos-de-prova prismáticos, com 28 dias de idade. A retração linear das argamassas foi determinada em um aparelho comparador, segundo a NBR 8490 (ABNT, 1984), em barras com 25x25x285mm com pinos fixados em suas extremidades.

Para análise da evolução da fissuração dos revestimentos de argamassa, foi utilizado um substrato cerâmico sobre o qual foi aplicada a argamassa de revestimento. Para a aplicação dos revestimentos foi utilizado uma caixa de queda, com altura de um metro, para padronizar a intensidade de força aplicada sobre a superfície do substrato, baseado nos estudos realizados por Masuero, Stolz e Antunes (2012). Após a aplicação do revestimento de argamassa, as amostras ficaram na sala com temperatura e umidade controladas e foram realizados registros fotográficos da superfície revestida. A partir das imagens obtidas, foram realizadas medições da área de fissuras existente em cada exemplar. $\mathrm{O}$ acompanhamento da evolução da fissuração foi realizado até os 28 dias.

\section{Apresentação e análise dos resultados \\ Propriedades das argamassas no estado fresco}

O índice de consistência por espalhamento das argamassas variou entre 256 e $264 \mathrm{~mm}$, ficando dentro da tolerância estabelecida na norma. Os resultados do ensaio de Squeeze-flow podem ser visualizados na Figura 4. A quantidade de água utilizada em cada traço de argamassa pode ser visualizada na Tabela 5, onde estão sumarizadas as propriedades das argamassas no estado fresco.

No ensaio de Squeeze-flow, a argamassa confeccionada com a areia de rio (AN 1,5) apresentou um perfil típico de deformação plástica (que é um comportamento adequado para a aplicação da argamassa), sendo que nas argamassas com areia de britagem este é seguido por um segundo estágio onde o comportamento se altera para enrijecimento por deformação (onde há um aumento substancial da carga necessária para continuar a deformação da argamassa, que resulta em dificuldades nas atividades de aplicação e acabamento do revestimento). Percebe-se uma clara alteração na trabalhabilidade das argamassas com areia de britagem, em relação à argamassa de referência confeccionada com areia de rio. Nas argamassas com areia de britagem, a argamassa com 1,5\% de adição de filer apresentou muito baixa trabalhabilidade e enrijecimento brusco, sendo impossível sua aplicação. Considerando que a distribuição quantitativa de constituintes nas argamassas AB1.5 e AN1.5 é similar, conclui-se que o motivo deste comportamento está relacionado às características da areia de britagem, como forma e textura superficial. Outro fator que justifica a menor trabalhabilidade da argamassa com areia de britagem no ensaio de squeeze-flow é a separação de fases que ocorre na amostra com 
$\mathrm{AB}$ em função da elevação do teor de água da mistura (19,8\% para $23,3 \%)$ : durante o ensaio, há migração de água para a borda da amostra e maior concentração de sólidos na região central, prejudicando a movimentação das partículas. Entretanto, à medida em que é adicionado um maior teor de filer, a argamassa apresenta maior deslocamento sob ação do carregamento, o que denota maior trabalhabilidade. Nas argamassas com adição entre 10 e $20 \%$ de filer já existe uma trabalhabilidade mais próxima à da areia de rio, adequada para a sua aplicação. Além da argamassa de referência, somente as argamassas com areia de britagem com adição de 10 a $30 \%$ de filer se enquadraram na faixa de "trabalhabilidade adequada para aplicação do revestimento". (Os limites de trabalhabilidade considerados adequados foram definidos no trabalho de Metz (2011), que utilizou o mesmo tipo de agregado e identificou faixas de trabalhabilidade que garantem uma adequada aplicação manual destas argamassas de revestimento).

A areia de britagem aumentou a demanda de água em mais de $15 \%$, em relação ao traço com areia natural de rio (AB1,5 x AN1,5). A diferença de demanda de água e de trabalhabilidade em função do tipo de areia é decorrente da forma e textura superficial dos grãos, uma vez que a distribuição granulométrica dos dois agregados foi equiparada.
Embora a trabalhabilidade da argamassa AB 1.5 seja muito baixa, nos demais traços o aumento do teor de filer resultou em melhor trabalhabilidade, e diminuiu gradativamente a demanda de água das argamassas, até uma diminuição de cerca de $10 \%$ do teor de água total da mistura, no teor de adição de $30 \%$. Observa-se na Figura 3 que à medida em que se acrescenta mais filer de britagem ocorrem simultaneamente diminuição no consumo de aglomerantes, aumento do teor de pasta (que afasta as partículas do aglomerante - o aumento é visível na Figura 3), diminuição da finura dos agregados utilizados (em função da finura do filer ser muito menor que a do agregado de britagem), e um pequeno aumento no teor de ar incorporado, fatores que em conjunto propiciaram diminuição do teor de água e, simultaneamente, acréscimo de trabalhabilidade às argamassas.

Em todos os traços foi utilizada cal, o que resultou em pequenos teores de ar incorporado quando comparados a argamassas sem a utilização da cal. Nas argamassas com areia de britagem, há uma tendência de acréscimo do teor de ar incorporado em função do teor de adição de finos. Como visto no ensaio de squeeze-flow (Figura 4) o aumento do teor de finos resultou em maior viscosidade da argamassa, o que impede que as bolhas de ar incorporado sejam expulsas da mistura.

\section{Figura 4 - Curvas carga versus deslocamento obtidas a partir de ensaio de Squeeze-flow}

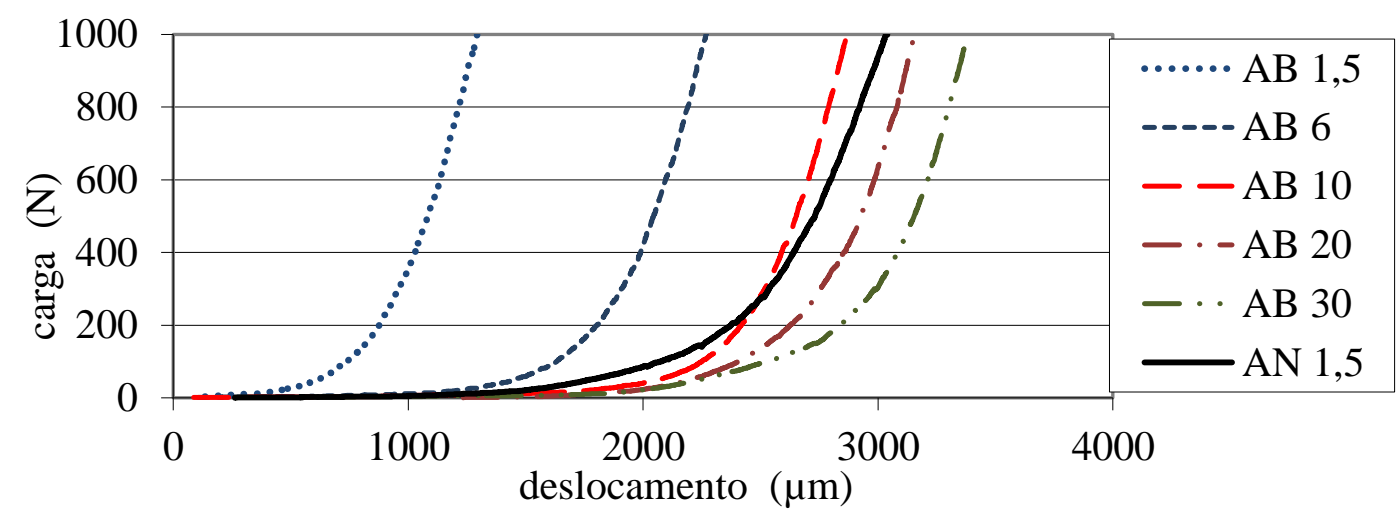

Tabela 5 - Propriedades das argamassas no estado fresco

\begin{tabular}{|c|c|c|c|c|}
\hline & $\begin{array}{c}\text { Teor de água } \\
(\%)\end{array}$ & $\begin{array}{c}\text { Densidade de massa } \\
(\mathrm{g} / \mathrm{cm} 3)\end{array}$ & $\begin{array}{c}\text { Ar incorporado } \\
(\%)\end{array}$ & $\begin{array}{c}\text { Retenção de agua } \\
(\%)\end{array}$ \\
\hline AN1.5 & 19,8 & 2,02 & 4,4 & 97 \\
\hline AB 1.5 & 23,3 & 2,10 & 2,5 & 97 \\
\hline AB6 & 22,6 & 2,12 & 2,5 & 98 \\
\hline AB10 & 21,8 & 2,12 & 2,6 & 98 \\
\hline AB20 & 20,7 & 2,14 & 3 & 98 \\
\hline AB30 & 20,4 & 2,15 & 3 & 98 \\
\hline
\end{tabular}


Todos os valores de densidade de massa no estado fresco foram elevados, o que classifica todas as argamassas na classe D6, segundo a NBR 13281 (ABNT, 2005g). A diferença de densidade de massa entre a argamassa de referência e a argamassa com areia de britagem AB1.5 é creditada à principalmente à diferença de massa específica entre os dois tipos de areia. Nas argamassas com areia de britagem, à medida em que se aumenta o teor de adição de filer, a densidade de massa da argamassa se torna maior, o que é creditado principalmente à diminuição do teor de água, que se soma ao acréscimo do teor de filer (cuja massa específica é de $2,70 \mathrm{~g} / \mathrm{cm}^{3}$ ).

Apesar da grande diferença da quantidade de filer de areia de britagem adicionados nas argamassas não houve variações significativas na retenção de água, constatação também encontrada por Tristão (2005). Todos os valores de retenção de água foram elevados, possivelmente em função do uso de cal hidratada $\mathrm{CH}-\mathrm{I}$.

\section{Propriedades das argamassas no estado endurecido}

Na Tabela 6 estão sumarizadas as propriedades das argamassas no estado endurecido.

Observa-se um pequeno aumento na resistência a compressão nos traços com areia de britagem comparativamente ao da areia natural, em acordo com os trabalhos de Silva, Buest e Campiteli (2005), apesar do teor de água da argamassa com areia de rio ser menor. Este fenômeno possivelmente decorre do melhor empacotamento dos grãos a partir da adição de finos de britagem na argamassa com areia de britagem, e da menor demanda de água decorrente da adição de finos à mistura, e é coerente com os valores obtidos na densidade de massa das argamassas. Observa-se, a partir da distribuição de poros das argamassas endurecidas (Figura 5), que em todas as argamassas com areia de britagem onde foi adicionado filer de britagem houve um refinamento de poros em relação à argamassa com areia natural, na faixa entre $0,5 \mu \mathrm{m}$ e $5 \mu \mathrm{m}$, que justifica a hipótese anterior. Descarta-se um possível efeito de pozolanicidade dos finos de areia de britagem, pois estes não foram classificados como pozolânicos, em ensaio realizado conforme a NBR 5752 (ABNT, 2012).

Tabela 6 - Propriedades das argamassas no estado endurecido

\begin{tabular}{c|c|c|c|c|c|c|c}
\hline & $\begin{array}{c}\text { Resistência à } \\
\text { compressão }\end{array}$ & $\begin{array}{c}\text { Resistência } \\
\text { à flexão }\end{array}$ & $\begin{array}{c}\text { Densidade } \\
\text { de massa }\end{array}$ & $\begin{array}{c}\text { Módulo } \\
\text { dinâmico* }\end{array}$ & $\begin{array}{c}\text { Índice de } \\
\text { vazios }\end{array}$ & $\begin{array}{c}\text { Absorção de } \\
\text { água total }\end{array}$ & $\begin{array}{c}\text { Coeficiente de } \\
\text { capilaridade }\end{array}$ \\
\hline & $\mathrm{MPa}$ & $\mathrm{MPa}$ & $\mathrm{g} / \mathrm{cm} 3$ & $\mathrm{GPa}$ & $\%$ & $\%$ & $\mathrm{c}$ \\
\hline $\mathrm{AN1.5}$ & 2,7 & 0,8 & 1,81 & 4,1 & 29,2 & 16 & 16 \\
$\mathrm{AB} 1.5$ & 3,2 & 0,9 & 1,85 & 3,7 & 33,2 & 18 & 21 \\
$\mathrm{AB} 6$ & 3,5 & 1,0 & 1,87 & 3,8 & 32,5 & 17 & 20 \\
$\mathrm{AB} 10$ & 3,8 & 1,1 & 1,88 & 4,0 & 32,0 & 17 & 19 \\
$\mathrm{AB} 20$ & 3,9 & 1,1 & 1,92 & 3,7 & 31,0 & 16 & 18 \\
$\mathrm{AB} 30$ & 3,7 & 1,0 & 1,92 & 4,1 & 31,0 & 16 & 19 \\
\hline
\end{tabular}

Figura 5 - Distribuição de poros das argamassas, obtida por PIM

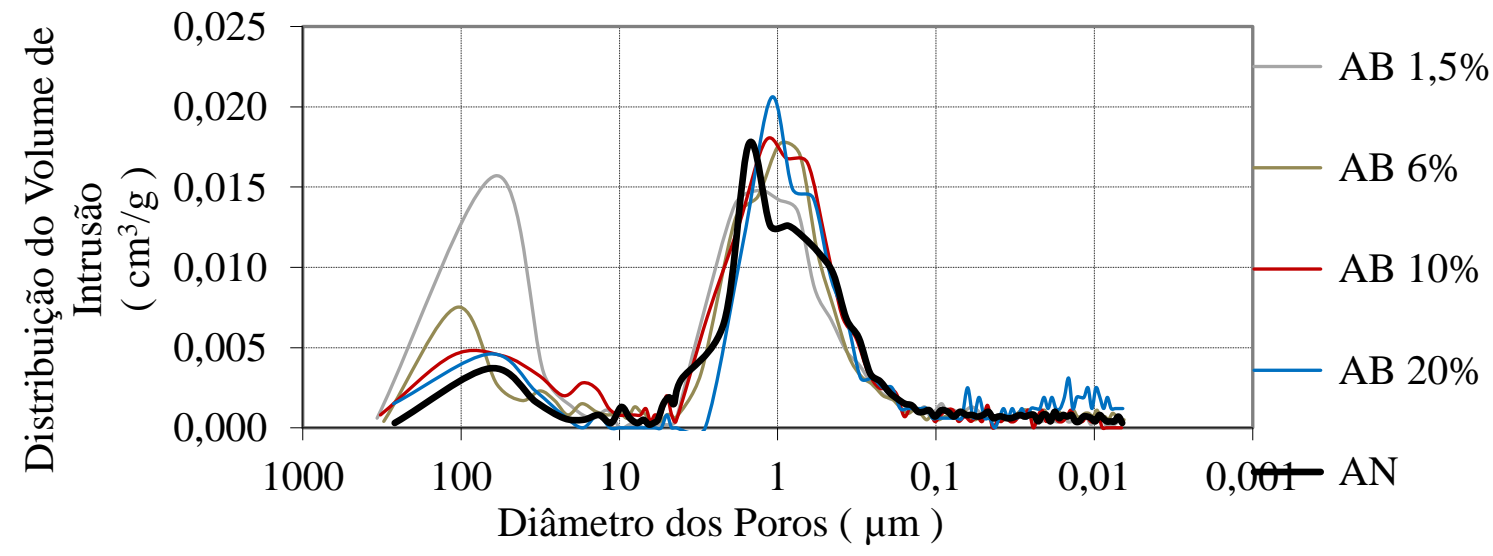

14 Kazmierczak, C. de S.; Rosa, M.; Arnold, D. C. M. 
Os resultados de resistência à compressão são coerentes com os trabalhos de D'Agostino (2004), Pandolfo e Masuero (2005) e Silva (2006), onde as argamassas com areia de britagem apresentaram maior resistência à compressão quando comparadas com areia de rio. A resistência à tração na flexão apresenta um comportamento semelhante ao da resistência à compressão.

As argamassas com areia de britagem apresentaram densidade de massa pouco superior as argamassas com areia natural e um pequeno acréscimo proporcional ao aumento de adição de filer, o que é coerente com as diferenças de massa específica entre os agregados $\left(2,60 \mathrm{~g} / \mathrm{cm}^{3}\right.$ para areia natural e $2,70 \mathrm{~g} / \mathrm{cm}^{3}$ para a areia de britagem). O módulo de elasticidade dinâmico das argamassas ficou na mesma ordem de grandeza, entre 3,7 e 4,1 $\mathrm{GPa}$, possivelmente devido à pequena variação na densidade de massa, que é o principal fator que rege o módulo de elasticidade.

Apesar de apresentarem maior resistência, as argamassas com areia de britagem possuem maior coeficiente de capilaridade que a argamassa de referência, e embora este coeficiente diminua a medida em que se acrescente o filer, até o teor de adição de $20 \%$, ainda se mantêm superior ao da argamassa de referência. Observa-se na curva de distribuição de poros que todas as argamassas com areia de britagem possuem maior quantidade de poros capilares e de macroporos. Todos os coeficientes de capilaridade são muito elevados, superiores a 10, valor limite definido pela NBR 13281 (ABNT, 2005g).
A Figura 6 apresenta os resultados dos ensaios de retração linear das argamassas.

A determinação da retração linear com uso de aparelho comparador somente pode ser iniciada após 48 da moldagem, quando as barras apresentaram resistência suficiente para desmoldagem e manuseio. Deste modo, o efeito da elevada retenção de água das argamassas (entre 97 e 98\%) não pode ser percebido, e uma parcela substancial da retração total, ocorrida neste período, não foi medida. No início das medições da retração nas barras de argamassa, verificou-se uma retração acentuada, com pouca diferença de comportamento entre as diversas argamassas. A partir da segunda semana, houve uma sensível diminuição na intensidade de retração, e uma maior distinção no comportamento entre as argamassas.

As argamassas com areia de britagem apresentaram maior retração à medida em que se aumentou o teor de finos adicionado ao traço, em consonância ao comportamento citado por diversos autores (SBRIGUI NETO, 1975; SILVA; BUEST; CAMPITELI, 2005). Observa-se que o teor de ar incorporado nas argamassas com areia de britagem, determinado no estado fresco, aumenta em função do teor de finos adicionado, e que aos 28dias, já no estado endurecido, o índice de vazios das argamassas apresenta um comportamento inverso a este (sendo menor nas argamassas com maior teor de finos), o que demonstra que ao longo do processo de cura houve uma diminuição no volume de vazios, principalmente nas argamassas com a maior adição de finos.

Figura 6 - Retração linear das argamassas

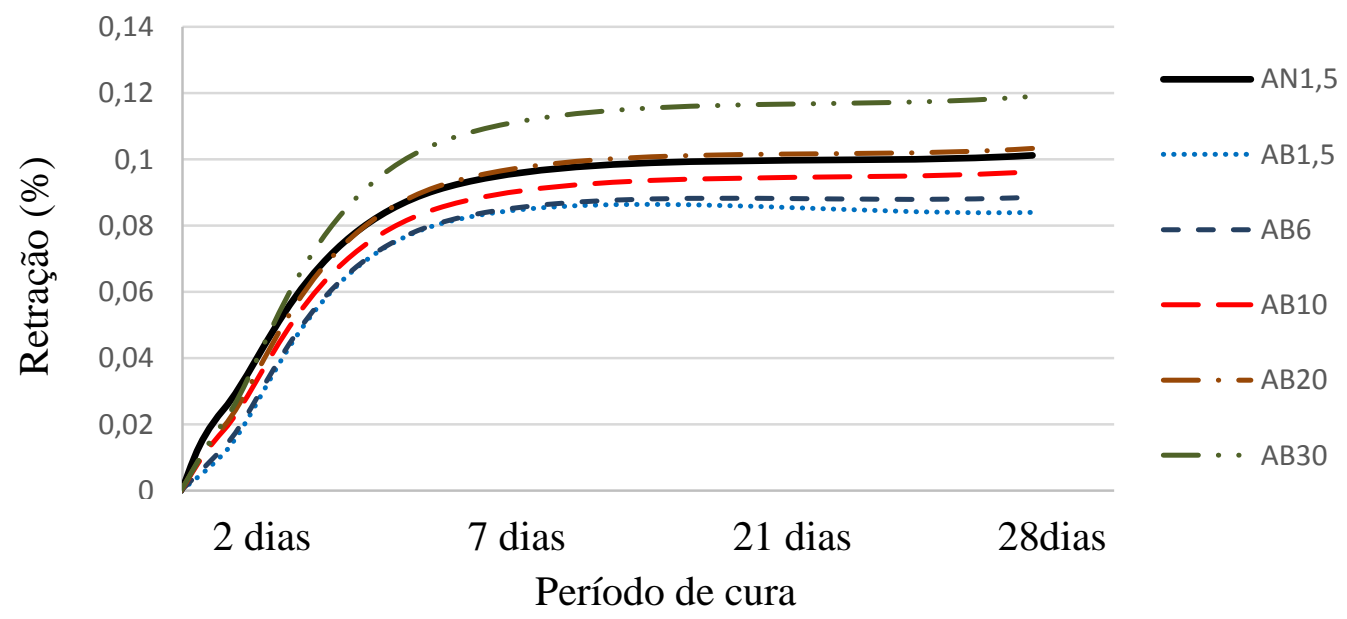


Ao se comparar a retração da argamassa de referência com as argamassas com areia de britagem, observa-se que as argamassas com areia de britagem com baixos teores de filer apresentaram os melhores resultados (menor retração), ficando a argamassa de referência com uma retração intermediaria. Nas argamassas de areia de britagem com baixo teor de filer $(1,5 \mathrm{e}$ $6 \%$ ) o teor de areia é similar ao da argamassa com areia de rio. A partir dos teores de adição de $10 \%$ e superiores, o teor de areia da mistura diminui substancialmente (aumentando o teor relativo de pasta na mistura), gerando uma maior retração.

\section{Avaliação da fissuração no revestimento}

A evolução da fissuração das argamassas aplicadas sobre substrato de cerâmica vermelha pode ser visualizada na Figura 7 (são apresentadas apenas as argamassas de revestimento que apresentaram fissuras visíveis, correspondentes às argamassas com areia de britagem com adição de 10\%, $20 \%$ e $30 \%$ de filer).

Para as características do substrato utilizado e as condições de cura adotados na pesquisa (temperatura de $23 \pm 2{ }^{\circ} \mathrm{C}$ e umidade relativa do ar de $60 \pm 5 \%$ ), o aparecimento de fissuras visíveis ocorreu apenas nas argamassas com areia de britagem e adição de finos igual ou superior a $10 \%$. Assim como no ensaio de retração em barras, as argamassas preparadas com maior teor de finos apresentaram maior fissuração. Ensaios realizados por Paes et al. (1999), demonstraram que maiores quantidades de finos adicionados à argamassa resultam em maior fissuração. Para os materiais utilizados neste estudo, observa-se que o máximo teor de adição de filer de britagem basáltico possível é de $10 \%$.

\section{Análise global dos resultados}

A adição de finos de britagem em argamassas confeccionadas com areia de britagem melhora a sua trabalhabilidade, permitindo a diminuição do teor de água para que a consistência especificada por meio do ensaio de mesa de espalhamento seja atingida. Entretanto, a adição e finos gera alterações reológicas na mistura (não detectadas pelo ensaio de espalhamento), ocorrendo uma redução substancial na carga necessária para deformar a argamassa, que pode ser constatado pelo ensaio de Squeeze-flow. Nos traços estudados, houve uma sensível diferença na trabalhabilidade das misturas, e apenas o traço de referência (com areia de rio) e os de areia de britagem com ao menos $10 \%$ de adição de finos se mostraram adequados para as operações de aplicação e acabamento do revestimento.

O aumento do teor de filer permitiu uma diminuição no teor de água da mistura, resultou em um pequeno acréscimo na densidade de massa das argamassas frescas, e foi acompanhado por um aumento no teor de ar incorporado à argamassa.

Aos 28 dias de idade, o índice de vazios da argamassa com areia de britagem endurecida é cerca de $10 \%$ maior que o da argamassa com a areia de referência (que possui um índice de vazios de 29,2\%), e diminui à medida em que há acréscimo de filer, até quase se equiparar ao da referência. A absorção de água total da argamassa endurecida segue o mesmo comportamento. As argamassas com areia de britagem possuem maior resistência a compressão que a argamassa de referência, e esta resistência aumenta à medida em que se aumenta o teor de adição de filer, até o teor de $20 \%$. O mesmo comportamento é observado na resistência a tração por compressão diametral.

Figura 7 - Evolução da fissuração nos revestimentos

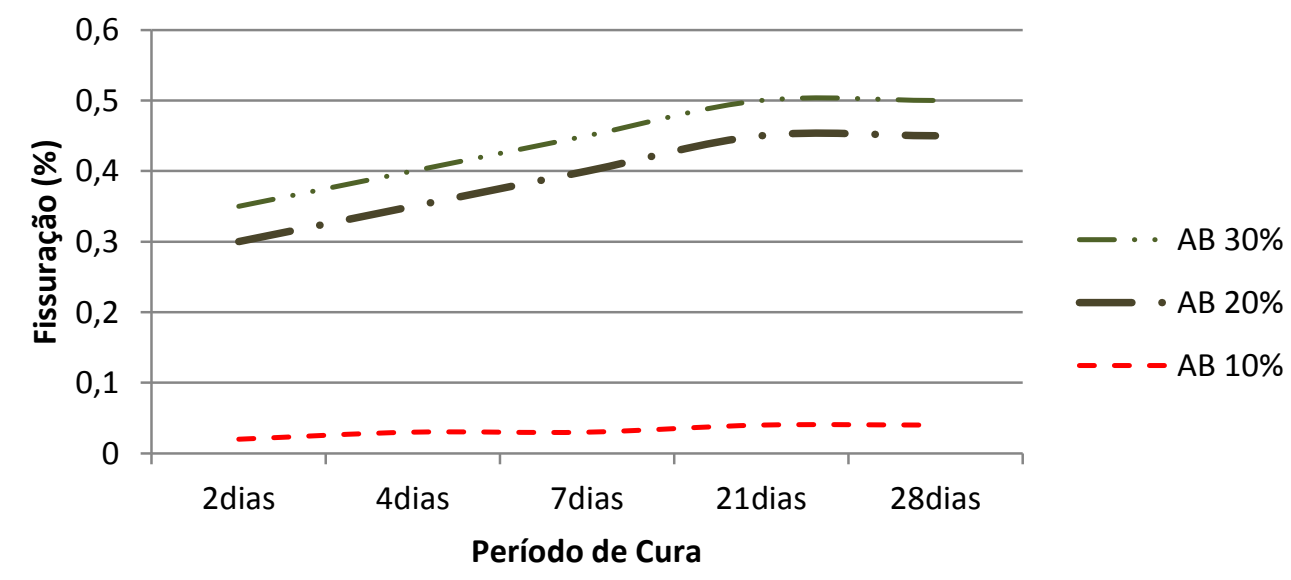

16 Kazmierczak, C. de S.; Rosa, M.; Arnold, D. C. M. 
A retração em barras de argamassa aumenta proporcionalmente ao teor de finos de britagem. Quando as argamassas foram aplicadas sobre o substrato cerâmico, aquelas com teores de 10, 20 e $30 \%$ de filer apresentaram fissuras visíveis, o que impossibilita o seu uso sobre o substrato adotado neste estudo.

Os resultados obtidos chamam a atenção para o fato de que mesmo havendo um aumento de resistência mecânica e diminuição do índice de vazios nas argamassas à medida em que se adiciona filer de britagem, o teor de finos deve ser avaliado de modo a garantir a ausência de fissuração no revestimento. É importante ressaltar que o teor máximo de adição de finos de britagem irá depender das características do substrato sobre o qual a argamassa será aplicada, pois este irá influenciar a velocidade em que irá ocorrer a perda de água da argamassa.

\section{Conclusão}

A adição de finos de britagem provenientes de britadores do tipo VSI em argamassas com areia de britagem é uma alternativa para melhorar a trabalhabilidade destas argamassas, com o objetivo de permitir a sua aplicação em revestimentos. A adição de finos resulta em menor necessidade de água de amassamento, maior resistência mecânica, menor exsudação, menor índice de vazios da argamassa endurecida e menor absorção de água. Porém, ocorre um pequeno aumento na densidade de massa e, principalmente, aumento na retração da argamassa. Para os materiais utilizados neste estudo, a adição de um teor entre 6 e $10 \%$ de finos de britagem à argamassa confeccionada com areia de britagem permitiu o ajuste da trabalhabilidade e a obtenção de uma argamassa sem fissuração por retração.

\section{Referências}

AHN, N. S. Experimental Study on the Guidelines For Using Higher Contents of Aggregate Micro Fines in Portland Cement Concrete. PhD Thesis - The University of Texas at Austin, 2000.

\section{ASSOCIAÇÃO BRASILEIRA DE NORMAS} TÉCNICAS. NBR 5752: pozolanas: determinação do índice de atividade pozolânica com cimento Portland: método de ensaio. Rio de Janeiro, 2012.

ASSOCIAÇÃO BRASILEIRA DE NORMAS TÉCNICAS. NBR 8490: argamassas endurecidas para alvenaria estrutural: retração por secagem: método de ensaio. Rio de Janeiro, 1984.
ASSOCIAÇÃO BRASILEIRA DE NORMAS TÉCNICAS. NBR 9778: argamassa e concreto endurecidos: determinação da absorção de água, índice de vazios e massa específica. Rio de Janeiro, 2009.

ASSOCIAÇÃO BRASILEIRA DE NORMAS TÉCNICAS. NBR 9935: agregados: terminologia. Rio de Janeiro, 2011.

\section{ASSOCIAÇÃO BRASILEIRA DE NORMAS} TÉCNICAS. NBR 13276: argamassa para assentamento e revestimento de paredes e tetos: preparo da mistura e determinação do índice de consistência. Rio de Janeiro, 2005a.

\section{ASSOCIAÇÃO BRASILEIRA DE NORMAS}

TÉCNICAS. NBR 13277: argamassa para assentamento e revestimento de paredes e tetos: determinação da retenção de água. Rio de Janeiro, 2005c.

\section{ASSOCIAÇÃO BRASILEIRA DE NORMAS TÉCNICAS. NBR 13278: argamassa para} assentamento de paredes e revestimento de paredes e tetos: determinação da densidade de massa e teor de ar incorporado. Rio de Janeiro, 2005b.

\section{ASSOCIAÇÃO BRASILEIRA DE NORMAS}

TÉCNICAS. NBR 13279: argamassa para assentamento e revestimento de paredes e tetos: determinação da resistência à tração na flexão e à compressão. Rio de Janeiro: 2005d.

\section{ASSOCIAÇÃO BRASILEIRA DE NORMAS} TÉCNICAS. NBR 13280: argamassa para assentamento e revestimento de paredes e tetos: determinação da densidade de massa aparente no estado endurecido. Rio de Janeiro: 2005e.

\section{ASSOCIAÇÃO BRASILEIRA DE NORMAS}

TÉCNICAS. NBR 15259: argamassa para assentamento e revestimento de paredes e tetos: determinação da absorção de água e do coeficiente de capilaridade. Rio de Janeiro, $2005 \mathrm{f}$.

\section{ASSOCIAÇÃO BRASILEIRA DE NORMAS} TÉCNICAS. NBR 13281: argamassa para assentamento e revestimento de paredes e tetos: requisitos. Rio de Janeiro, 2005g.

\section{ASSOCIAÇÃO BRASILEIRA DE NORMAS TÉCNICAS. NBR 15839: argamassa de assentamento e revestimento de paredes e tetos: caracterização reológica pelo método Squeeze- flow. Rio de Janeiro, 2010.}

\section{ASSOCIAÇÃO BRASILEIRA DE NORMAS} TÉCNICAS. NBR NM 47: concreto: determinação do teor de ar em concretos frescos: método pressiométrico. Rio de Janeiro, 2002. 
ASSOCIAÇÃO BRASILEIRA DE NORMAS TÉCNICAS. NBR 8802: concreto endurecido: determinação da velocidade de onda ultrassônica. Rio de Janeiro, 1985.

BAUER, E.; SOUSA, J. G. G. Materiais Constituintes e Suas Funções. In: BAUER, E. (Org.). Revestimentos de Argamassa: características e peculiaridades. Brasília: SINDUSCON-DF, LEM-UnB, 2005. v. 1.

CARDOSO, F. A. et al. Squeeze-Flow Aplicado a Argamassas de Revestimento: manual de utilização. São Paulo, 2010. Boletim Técnico da Escola Politécnica da USP. Departamento de Engenharia de Construção Civil. BT/PCC/545.

D’Agostino, L. Z. Uso de Finos de Pedreira no Processo de Argamassas de Assentamento. São Paulo, 2004. Dissertação (Mestrado em Engenharia Civil) - Escola Politécnica, Universidade de São Paulo, São Paulo, 2004.

GONÇALVES, J. P. et al. Comparison of Natural and Manufactured Fine Aggregates in Cement Mortars. Cement and Concrete Research, v. 37, n. 6, p. 924-932, 2007.

HARINI, M; SHAALINI, G.; DHINAKARAN, G. Effect of Size and Type of Fine Aggregates on Flowability of Mortar. KSCE Journal of Civil Engineering, v. 16, n. 1, p.163-168, 2012.

\section{INTERNATIONAL ORGANIZATION FPR} STANDARDIZATION. ISO 13320-1: particle size analysis: laser diffraction methods: part 1: general principles. 1999. : ISO TC 24/SC.

MASUERO, A. B; STOLZ, C. M; ANTUNES, G. R. Análise da Influência do Equipamento Utilizado no Ensaio de Resistência de Aderência à Tração. In: CONGRESSO PORTUGUÊS DE ARGAMASSAS, 4., Lisboa, 2012. Anais... Lisboa, APFAC, 2012.

METZ, D. Análise da Influência da Forma dos Grãos nas Propriedades das Argamassas. São Leopoldo, 2011. Dissertação (Mestrado em Engenharia Civil) - Faculdade de Engenharia, Universidade do Vale do Rio dos Sinos, São Leopoldo, 2011.

MIRANDA, L. F. R; SELMO, S. M. CDW Recycled Aggregate Renderings: part II: analysis of the effect of materials finer than $75 \mu \mathrm{m}$ under accelerated aging performance. Construction and Building Materials, v. 20, n. 9, p. 625-633, 2006.
PANDOLFO, L. M.; MASUERO, A. B. Características das Areias de Basalto que Influenciam nas Propriedades das Argamassas. In: SIMPÓSIO BRASILEIRO DE TECNOLOGIA DAS ARGAMASSAS, 6.; INTERNACIONAL SYMPOSIUM. ON MORTARS TECHNOLOGY, Florianópolis, 2005. Anais... Florianópolis: ANTAC, 2005.

PAES, I. N. L. et al. O Efeito de Finos Calcários nas Propriedades da Argamassa de Revestimento. In: SIMPÓSIO BRASILEIRO DE TECNOLOGIA DAS ARGAMASSAS, 3., Vitória, 1999. Anais... Vitória: UFES, 1999.

SAMPAIO, R. G.; BASTOS, P. K. X. Estudo da Granulometria de Areia de Britagem Para Argamassas de Revestimento. In: SIMPÓSIO BRASILEIRO DE TECNOLOGIA DAS ARGAMASSAS, 8., Curitiba, 2009. Anais... Curitiba: ANTAC, 2009.

SARAIVA, A. G.; BAUER, E.; GONCALVES, S. R. C. Variabilidade de Aderência de Revestimentos de Argamassa. Téchne: Revista de Tecnologia da Construção, São Paulo, v. 6, p. 7074, 2010.

SBRIGHI NETO, C. A Influência da Natureza Petrográfica da Areia Britada e de seus Finos em Algumas Propriedades do Betão. Lisboa, 1975. 102 f. Dissertação (Mestrado em Engenharia Civil) - Laboratório Nacional de Engenharia Civil, Lisboa, 1975.

SILVA, N. G.; BUEST, G.; CAMPITELI, V. C. Argamassas Com Areia Britada: influência dos finos e da forma das partículas. In: SIMPÓSIO BRASILEIRO DE TECNOLOGIA DAS ARGAMASSAS, Florianópolis, 2005. Anais... Florianópolis: UFSC, 2005.

SILVA, N. G. Argamassa de Revestimento de Cimento, Cal e Areia Britada de Rocha Calcária. Curitiba, 2006. Dissertação (Mestrado em Engenharia Civil) - Escola de Engenharia, Universidade Federal do Paraná, Curitiba, 2006.

TRISTÃO, F. A. Influência dos Parâmetros Texturais das Areias nas Propriedades das Argamassas Mistas de Revestimento. Florianópolis, 2005. Tese (Doutorado em Engenharia Civil) - Escola de Engenharia, Universidade Federal de Santa Catarina, Florianópolis, 2005.

WESTERHOLM, M. et al. Influence of Fine Aggregate Characteristics on the Rheological Properties of Mortars. Cement and Concrete Composites, v. 30, n. 4, p. 274-282, 2008. 


\section{Agradecimentos}

Os autores agradecem à CAPES pela bolsa de estudos concedida para a execução da parte experimental do trabalho.

Claudio de Souza Kazmierczak

Programa de Pós-Graduação em Engenharia Civil | Universidade do Vale do Rio dos Sinos | Av. Unisinos, 950, Cristo Rei | São Leopoldo RS - Brasil | Caixa Postal 275 | CEP 93022-750 | Tel.: (51) 3590-8245 | E-mail: claudiok@unisinos.br

\section{Mateus Rosa}

Programa de Pós-Graduação em Engenharia Civil | Universidade do Vale do Rio dos Sinos | E-mail: mateusrosars@uol.com.br

\section{Daiana Cristina Metz Arnold}

Instituto de Ciências Exatas e Tecnológicas | Universidade Feevale | Rod. RS-239, São José | Novo Hamburgo - RS - Brasil | CEP $93352-000$ | Tel.: (51) 3586-8800 | E-mail: daiana.metz@gmail.com

\section{Revista Ambiente Construído}

Associação Nacional de Tecnologia do Ambiente Construído

Av. Osvaldo Aranha, $99-3^{\circ}$ andar, Centro

Porto Alegre - RS - Brasil

CEP 90035-190

Telefone: +55 (51) 3308-4084

Fax: +55 (51) 3308-4054

www.seer.ufrgs.br/ambienteconstruido

E-mail: ambienteconstruido@ufrgs.br 